\title{
Effect of magnesium ion on human osteoblast activity
}

\author{
L.Y. He ${ }^{1,{ }^{*}}$, X.M. Zhang ${ }^{2, *}$, B. Liu ${ }^{1}$, Y. Tian ${ }^{1}$ and W.H. Ma ${ }^{1}$ \\ ${ }^{1}$ Department of Orthopedic Surgery, The Third Hospital of Hebei Medical University, The Key Laboratory for Orthopedic \\ Biomechanics of Hebei Province, Shijiazhuang, Hebei Province, China \\ ${ }^{2}$ Department of Orthopedic Surgery, Hebei National Defense Construction Hospital, Shijiazhuang, Hebei Province, China
}

\begin{abstract}
Magnesium, a promising biodegradable metal, has been reported in several studies to increase bone formation. Although there is some information regarding the concentrations of magnesium ions that affect bone remodeling at a cellular level, little is known about the effect of magnesium ions on cell gap junctions. Therefore, this study aimed to systematically investigate the effects of different concentrations of magnesium on bone cells, and further evaluate its effect on gap junctions of osteoblasts. Cultures of normal human osteoblasts were treated with magnesium ions at concentrations of 1,2 and $3 \mathrm{mM}$, for 24,48 and $72 \mathrm{~h}$. The effects of magnesium ions on viability and function of normal human osteoblasts and on gap junction intercellular communication (GJIC) in osteoblasts were investigated. Magnesium ions induced significant $(P<0.05)$ increases in cell viability, alkaline phosphate activity and osteocalcin levels of human osteoblasts. These stimulatory actions were positively associated with the concentration of magnesium and the time of exposure. Furthermore, the GJIC of osteoblasts was significantly promoted by magnesium ions. In conclusion, this study demonstrated that magnesium ions induced the activity of osteoblasts by enhancing GJIC between cells, and influenced bone formation. These findings may contribute to a better understanding of the influence of magnesium on bone remodeling and to the advance of its application in clinical practice.
\end{abstract}

Key words: Magnesium; Osteoblast; Gap junction intercellular communication

\section{Introduction}

Over recent years, there has been a growing interest in magnesium and its alloys as novel internal fixation materials for bone fracture healing due to its biodegradability and mechanical properties (1-3). Magnesium implants can degrade via corrosion in the electrolytic environment of the body and mainly dissolve as divalent magnesium ions $\left(\mathrm{Mg}^{2+}\right)$. Repeated observations have shown enhanced bone growth around various degradable magnesium alloys in vivo. Hong et al. (4) directly cultured a murine osteoblast-like cell line (MC3T3) on Mg-4 wt.\% Zn-0.5 wt.\% Zr (ZK40) alloy and found favorable cell viability and attachment. Weng et al. (5) reported that nanostructured magnesium could influence the initial adsorption of proteins known to promote the function of osteoblasts. Furthermore, a clear stimulation of cell proliferation and an enhancement of the mitochondrial respiratory activity were observed when mouse osteoblasts (MC3T3-E1) were cultured with a fluoride surface-modified AZ31 magnesium alloy (AZ31HF), compared to bare-coated ones (6). Although current studies have reported on the relationship between magnesium material and bone formation, there is still no clear understanding regarding the effects of different concentrations of magnesium ions on bone cells.
In addition, efforts have been made to reveal the mechanism by which magnesium regulates bone remodeling. Rude et al. (7) demonstrated an increase in TNF- $\alpha$ in bone from magnesium deficient rodents, suggesting that TNF- $\alpha$ may play a role in magnesium deficiencyinduced bone loss. It was also reported that magnesium deficiency in the rat and/or mouse resulted in increased skeletal substance $\mathrm{P}$, which in turn stimulated production of cytokines and increased bone resorption by osteoclasts (8). Moreover, Abed (9) indicated that the influx of extracellular $\mathrm{Mg}^{2+}$ could enhance cell migration and stimulate gene expression of melastatin-like transient receptor potential 7 (TRPM7) channels in human osteoblast MG-63 cells, leading to bone formation. Although these data support the hypothesis that magnesium ion plays a particularly critical role in bone remodeling, the exact mechanism of this biological stimulus is still unclear.

Gap junctions formed by connexins (Cx) play an important role in transmitting signals between bone cells, which are responsible for bone formation and bone remodeling. Gap junctional intercellular communication

Correspondence: W.H. Ma: <hmq813@163.com>

*These authors contributed equally to this study.

Received December 21, 2015 | Accepted April 18, 2016 
(GJIC) has been demonstrated to mediate the process of osteoblast differentiation and bone formation (10). Furthermore, GJIC propagates $\mathrm{Ca}^{2+}$ signaling, conveys anabolic effects of hormones and growth factors, and regulates gene transcription of osteoblast differentiation markers $(10,11)$. To date, no information is available about the effects of magnesium ions on GJIC. Therefore, this study was performed to investigate the role of magnesium at different concentrations on osteoblast in terms of cell viability levels, alkaline phosphate (ALP) activity and osteocalcin determinations in culture supernatants. We also investigated for the first time the effects of magnesium ions on GJIC in osteoblasts.

\section{Material and Methods}

A normal human osteoblast cell line (hFOB1.19; ATCC, USA) was used in this study. The cells were cultured in Dulbecco Modified Eagle Medium (DMEM; Gibco, USA) supplemented with $10 \%$ fetal bovine serum (Gibco), $100 \mathrm{IU} / \mathrm{mL}$ penicillin and $100 \mu \mathrm{g} / \mathrm{mL}$ streptomycin. Incubation was conducted at $5 \% \quad \mathrm{CO}_{2}$ at $37^{\circ} \mathrm{C}$. The medium was changed every 2-3 days. Cells growing in medium without addition of $\mathrm{MgSO}_{4}$ were used as controls. $\mathrm{MgSO}_{4}$ was purchased from Tiancheng Pharmaceutical Co., Ltd. (China) and was diluted in serum-free DMEM to the specified concentrations.

\section{Cell proliferation and viability}

Cell proliferation and viability were measured by the MTT 3-(4,5-dimethylthiazol-2-yl)-2,5-diphenyltetrazolium bromide assay. Cells were seeded onto a 96 -well plate (clear bottom), at a density of 10,000 cells per well in $100 \mu \mathrm{L}$ medium, incubated for $24 \mathrm{~h}$, and treated with magnesium ions at final concentrations of 1,2 and $3 \mathrm{mM}$, using 6 replicates per concentration per treatment. After 24, 48 and $72 \mathrm{~h}, 20 \mu \mathrm{L}$ of $5 \mathrm{mg} / \mathrm{mL}$ MTT solution were added to each well and incubated in a humidified atmosphere of $5 \% \mathrm{CO}_{2}$ at $37^{\circ} \mathrm{C}$ for $5 \mathrm{~h}$. After incubation, the cells were washed with PBS solution. Subsequently, $100 \mu \mathrm{L}$ of isopropanol acid $4 \%$ and hydrochloric acid were added to each well, and cells were incubated at room temperature for $10 \mathrm{~min}$. The absorbance was measured by microplate reader (Synergy H4, USA) at $492 \mathrm{~nm}$, with $620 \mathrm{~nm}$ as reference.

\section{ALP activity}

The cells $\left(2 \times 10^{4}\right.$ cell in $\left.100 \mu \mathrm{L}\right)$ from the second passage were seeded on four 24-well plates and incubated for 3-5 days near confluence and were treated with magnesium ions at final concentrations of 1, 2 and $3 \mathrm{mM}$. After 24, 48 and $72 \mathrm{~h}$, the cells were measured for ALP activity. Analyses were performed using 6 replicates for each treatment. To assay the ALP activity, the remaining medium was removed, cells were washed with PBS and digested with $0.25 \%$ trypsin for $1 \mathrm{~min}$. The cell suspension was then collected in Eppendorf tubes, distilled water was added in each tube, and the mixture was frozen in liquid nitrogen and thawed repeatedly 3-4 times to destroy the cell membrane. After centrifugation at 10,732 $\mathrm{g}$ for $15 \mathrm{~min}$ at $-4^{\circ} \mathrm{C}$, the supernatants were collected for analysis according to the ALP kit (Elabscience, China) instructions, with an automatic biochemistry analyzer (Hitachi 7150, Japan) at $405 \mathrm{~nm}$. All treatments were compared against control wells (cell cultured in ordinary DMEM without magnesium).

\section{Osteocalcin assay}

The assay for osteocalcin was performed with enzyme-linked immunosorbent assay (ELISA). The cells were cultured and treated as described above. The supernatants were collected in Eppendorf tubes to perform the osteocalcin determinations according to the instructions of the osteocalcin kit (Elabscience). The absorbance was measured by a microplate reader (Synergy $\mathrm{H} 4$ ) at $450 \mathrm{~nm}$ and the corresponding value of osteocalcin was calculated according to the standard curve. A total of 6 replicates were used per treatment.

\section{GJIC in human osteoblasts}

Fluorescence recovery after photobleaching (FRAP) is a noninvasive technique that allows quantitative measurement of gap junction function in living cells. In the FRAP assay, diffusion-dependent redistribution of a gap junctionpermeable fluorescent dye following photobleaching is measured. In a fluorescently labeled cell that is in contact with other labeled cells, photobleaching results in a rapid decrease in fluorescence intensity followed by fluorescence increase over a period of time due to gap junctional activity. In the present study, the FRAP was used to determine the effect of the magnesium on GJIC in normal human osteoblasts. Cells were seeded into a 96-well plate, at a density of 5,000 cells per well, and incubated to confluence. Cells were rinsed twice with D-Hank's, treated with $10 \mu \mathrm{M}$ CFDA $(5,6$-carboxy fluorescein diacetate; Sigma, USA) at $37^{\circ} \mathrm{C}$ for $90 \mathrm{~min}$, and rinsed with D-Hank's again. Then, cells were treated with magnesium ions at final concentrations of 1,2 and $3 \mathrm{mM}$ for 24,48 and $72 \mathrm{~h}$, and their GJIC were measured with the MRC-1024 laser scanning confocal microscope imaging system (Bio-Rad, USA). The rate of fluorescence recovery $(R)$ at $10 \mathrm{~min}$ after photobleaching was adopted as the functional index of GJIC.

\section{Statistical analysis}

For each parameter of magnesium ion, mean and standard deviation for three concentrations at all time points are reported. The $t$-test was carried out to compare data between two groups and the multilevel test to compare data among three or more groups at different intervals. The SAS software package (version 9.1, SAS 

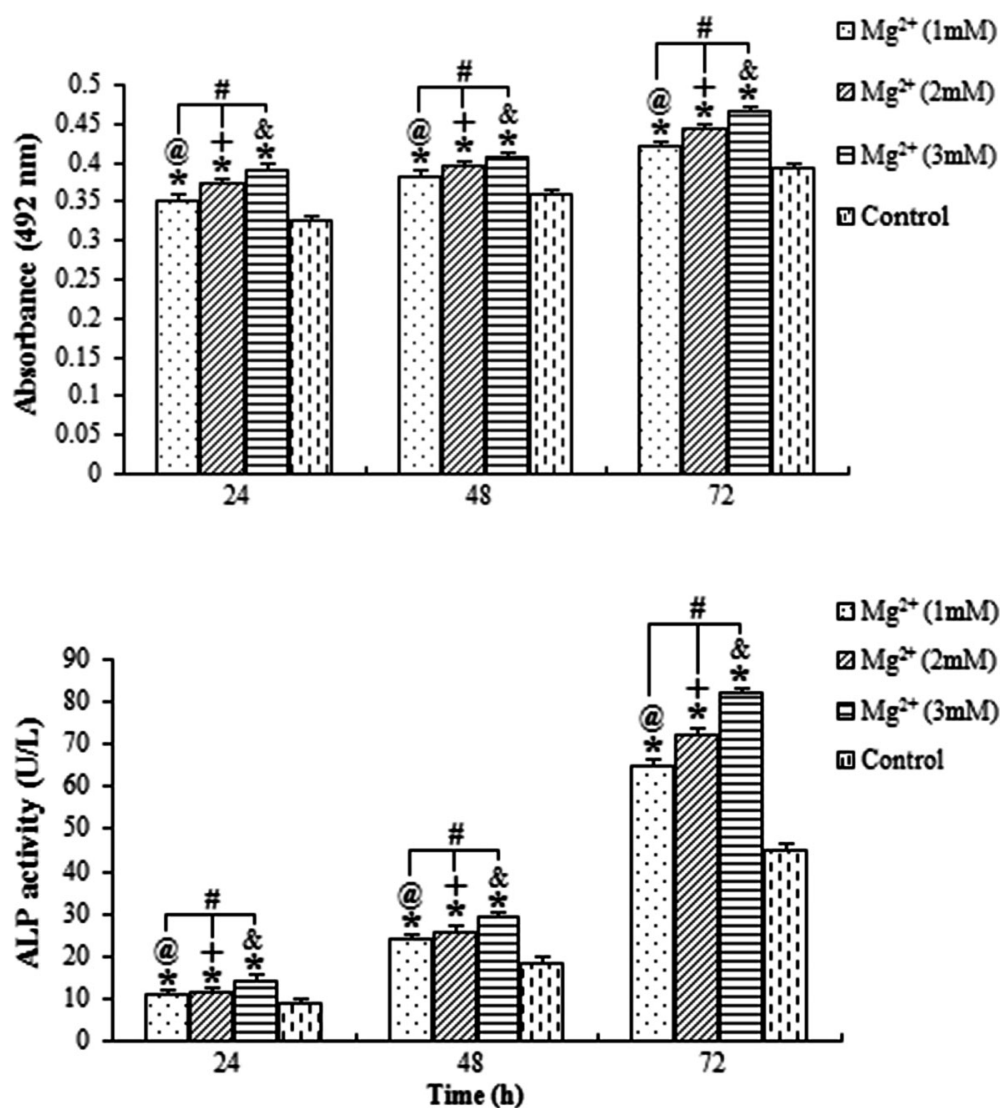

- $\mathrm{Mg}^{2+}(1 \mathrm{mM})$

$\nabla \mathrm{Mg}^{2+}(2 \mathrm{mM})$

$\nabla \mathrm{Mg}^{2+}(3 \mathrm{mM})$

四 Control
Figure 1. Average absorbance of osteoblasts treated with magnesium $\left(\mathrm{Mg}^{2+}\right)$. The absorbance of cells increased with the increasing concentration of $\mathrm{Mg}^{2+}$ and with longer exposure time. $@,+, \& P<0.05$, differences over time at concentrations of 1,2 and $3 \mathrm{mM}$, respectively. ${ }^{\#} \mathrm{P}<0.05$, differences among various concentrations of magnesium at each time point; ${ }^{*} \mathrm{P}<0.05$, differences from the control group at each time point (ANOVA).
Institute Inc., USA) was used for statistical analysis. Statistical significance was assigned to $\mathrm{P}<0.05$.

\section{Results}

\section{Cell proliferation and viability}

The proliferation index (absorbance) of the osteoblasts exposed to magnesium ions at the concentrations of 1, 2 and $3 \mathrm{mM}$ for 24, 48 and 72 were all significantly higher than those of the blank control group ( $P<0.05$; Figure 1). Additionally, the result revealed the interaction between the exposure time and the concentration of magnesium. Data indicated that the absorbance was positively associated with the concentration of magnesium and the duration of exposure.

\section{ALP activity and osteocalcin level}

The ALP activity and osteocalcin levels of osteoblasts exposed to the magnesium ions at the three concentrations were evaluated (Figures 2 and 3, respectively). All results showed that the stimulation action of $3 \mathrm{mM}$ magnesium for $72 \mathrm{~h}$ was the highest. The ALP activity and osteocalcin levels of osteoblasts treated with magnesium ions increased with higher concentrations of magnesium ions and longer exposure time.

\section{GJIC in human osteoblasts}

The ratios of fluorescence recovery $(R)$ of cells exposed to magnesium ions at the concentrations of 1,2 and $3 \mathrm{mM}$ for 24 , 48 and $72 \mathrm{~h}$ are shown in Figure 4. Compared to the control group, the GJIC of osteoblasts was significantly promoted by the magnesium $(P<0.05)$. Meanwhile, the highest $R$-value was found in cells exposed to $3 \mathrm{mM}$ magnesium for $72 \mathrm{~h}$, whereas the lowest was found in cells exposed to $1 \mathrm{mM}$ magnesium for $24 \mathrm{~h}$, suggesting that the R-value of cells was also positively associated with the concentration of magnesium ions and the duration of exposure.

\section{Discussion}

Recently, magnesium (Mg) alloys or Mg-coated surfaces of metallic substrates were introduced in medical applications $(12,13)$. A few studies have reported an increase in the attachment and functions of osteoblasts on the $\mathrm{Mg}$ surface $(14,15)$. Moreover, $\mathrm{Mg}$ is the fourth most abundant mineral in the human body, the second most abundant in intracellular medium and the most abundant in cartilage and bone tissue during the initial stages of osteogenesis (16). Some studies have demonstrated that magnesium ions play a momentous role in osteogenesis and bone remodeling (17-20). However, because of the complexity of the mechanisms regulating bone 

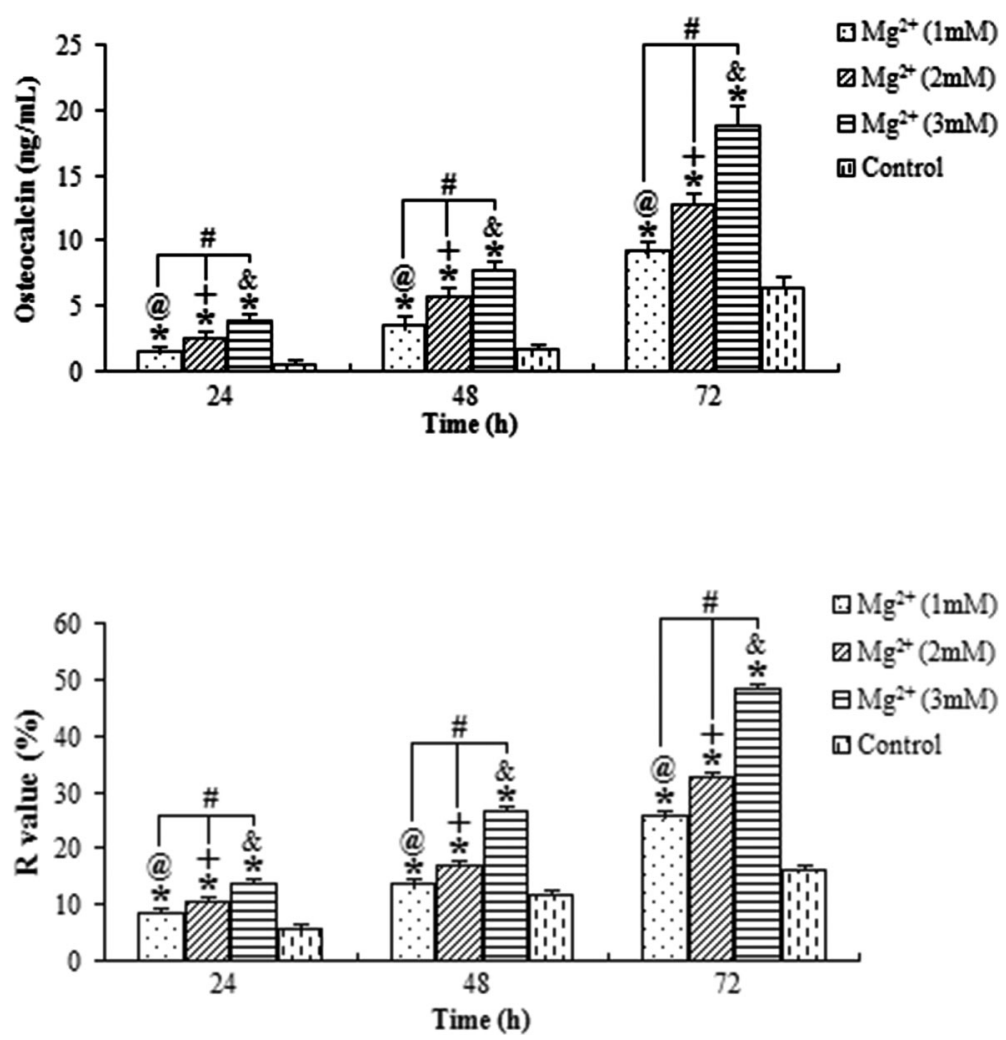

Figure 3. Average osteocalcin levels in osteoblasts treated with magnesium $\left(\mathrm{Mg}^{2+}\right)$. The stimulation action of $\mathrm{Mg}^{2+}$ was positively associated with concentrations of $\mathrm{Mg}^{2+}$ and time of exposure. @,$^{+, \&} \mathrm{P}<0.05$, for differences over time at concentrations of 1,2 and $3 \mathrm{mM}$, respectively. ${ }^{\#} \mathrm{P}<0.05$, for differences among various concentrations of $\mathrm{Mg}^{2+}$ at each time point. ${ }^{*} \mathrm{P}<0.05$, for differences from the control group at each time point (ANOVA). remodeling, the experimental and mechanistic studies based on in vivo murine genetic and pharmacological models had their limitations to some extent. Furthermore, previous studies $(4,6,9)$ based on osteoblastic cell lines mainly derived from animal or osteosarcoma have provided a better understanding of the action that was implicated in the control of osteoblasts activity and thus bone formation. Thus, we used the normal human osteoblast cell line in this study, which markedly improved the reliability of the research.

This study is unique in that it comprehensively investigated the dose-dependent effects of $\mathrm{Mg}$ ions on human osteoblasts, looking specifically at cellular proliferation and function. The effects of $\mathrm{Mg}$ ions at different concentrations on osteoblasts were also compared. The results showed that $\mathrm{Mg}$ ions increased not only cell viability but also cell differentiation. We used ALP activity and osteocalcin as markers for osteoblastic differentiation. All groups treated with $\mathrm{Mg}$ had dose-dependent up-regulation of ALP activities and osteocalcin levels compared with the control group. Several researchers have studied Mg actions on osteoblastic cell proliferation, differentiation, or function. Our results were in line with the study by Yang et al (21), who evaluated the effects of Mg alloys on the osteogenic differentiation of human bone marrow-derived stromal cells (hBMSCs) and found that Mg ion in the extracts, which was a result of the corrosion of Mg alloys, stimulated the viability and osteogenic differentiation of hBMSCs. Abed and Moreau (9) also demonstrated that the influx of $\mathrm{Mg}$ ions enhanced cell migration and stimulated the gene expression of TRPM7 channels in human osteoblast MG-63 cells. The stimulatory action of $\mathrm{Mg}$ ion on human osteoblasts indicated that it was involved in modulating bone metabolism in some way. However, the mechanism of action of Mg needs to be further investigated.

Many studies have been conducted to evaluate the osteogenic action of $\mathrm{Mg}$, but few have examined the effects of various concentrations of these ions. In the current study, osteoblasts viability was positively associated with the concentration of $\mathrm{Mg}$ ions and the duration of exposure. Higher concentrations had greater effects on osteoblasts viability. Our findings are in agreement with the experimental study performed by Yang et al. (21), which indicated that $\leqslant 10 \mathrm{mM}$ concentration of $\mathrm{Mg}$ ion in the extracts enhanced the viability and osteogenic differentiation of hBMSCs. Another recent study found that the increase of intracellular $\mathrm{Mg}$ concentration could stimulate the proliferation and migration of human osteoblast MG-63 cells (9). In contrast to our findings, however, Leidi et al. (22) reported that high $\mathrm{Mg}$ levels impaired osteoblast activity, which might therefore contribute to bone disease. Similarly, Kircelli et al. (23) found that higher Mg levels prevented the process of differentiation of bovine vascular smooth muscle cells into osteoblast-like cells and inhibited expression of osteogenic proteins, apoptosis and further progression of already established calcification. The 
different results in our study could be due to different study protocols, such as the various cell lines used in studies, the duration of culturing, the diluents for $\mathrm{Mg}$, and methods used to evaluate cell viability. Although we originally investigated three concentrations of $\mathrm{Mg}$ ions, the most effective dose of action is still not clear, and an extended dose range needs to be further tested.

Collectively, these results suggest that the $\mathrm{Mg}$ ion stimulated osteogenesis in human osteoblasts. Previously, it was observed that $\mathrm{Mg}$ depletion in rat and/or mouse increased osteoclastic bone resorption and inhibited bone formation. Also, $\mathrm{Mg}$ deficiency in humans has been associated with altered osteoblastic differentiation, reduced bone formation and the development of osteoporosis (8). These diverse data supported the hypothesis that Mg contributed to the maintenance of bone mass by regulating osteogenic activity in osteoblast. However, the mechanism for this action is still unclear. Signal factors, depending on their properties and their impact on messenger substance, can affect cell differentiation and bone formation. Furthermore, signal transmission has an essential role in cell activation. GJIC mediated by connexins, in particular connexin 43 (Cx43), plays important roles in regulating signal transmission among different bone cells, and thereby regulates development, differentiation, modeling and remodeling of the bone. Furthermore, osteocytes utilize GJIC to coordinate bone remodeling in response to anabolic factors and mechanical loading. These transmembrane channels allow continuity of cytoplasm and mediate the transfer of molecules between communicating cells (24-26). The biological importance of the communication mediated by connexinforming channels in bone development is revealed by the low bone mass and osteoblast dysfunction in the Cx43null mice and the skeletal malformations observed in occulodentodigital dysplasia caused by mutations in the Cx43 gene (27-30). However, there are no available data on the effects of the Mg ion on GJIC between osteoblasts so far.

\section{References}

1. Cho LR, Kim DG, Kim JH, Byon ES, Jeong YS, Park CJ. Bone response of $\mathrm{Mg}$ ion-implanted clinical implants with the plasma source ion implantation method. Clin Oral Implants Res 2010; 21: 848-856, doi: 10.1111/j.1600-0501.2009.01862.x.

2. Li Z, Gu X, Lou S, Zheng Y. The development of binary $\mathrm{Mg}-\mathrm{Ca}$ alloys for use as biodegradable materials within bone. Biomaterials 2008; 29: 1329-1344, doi: 10.1016/ j.biomaterials.2007.12.021.

3. Witte F, Hort N, Vogt C, Cohen S, Kainer KU, Willumeit R, et al. Degradable biomaterials based on magnesium corrosion. Curr Opin Solid State Mater Sci 2008; 12: 63-72, doi: 10.1016/j.cossms.2009.04.001.

4. Hong D, Saha P, Chou DT, Lee B, Collins BE, Tan Z, et al. In vitro degradation and cytotoxicity response of $\mathrm{Mg}-4 \%$ $\mathrm{Zn}-0.5 \% \mathrm{Zr}$ (ZK40) alloy as a potential biodegradable material. Acta Biomater 2013; 9: 8534-8547, doi: 10.1016/j.actbio. 2013.07.001.
The novelty of the current work is that we confirmed the stimulatory effect of $\mathrm{Mg}$ ion on GJIC in osteoblasts with the FRAP technique. The R-value of cells increased with increasing $\mathrm{Mg}$ ion concentrations and exposure time, suggesting that $\mathrm{Mg}$ ion regulated osteoblast activity via promotion of the GJIC between cells. This is further confirmed by the role of $\mathrm{Mg}$ in the mediation of osteoblast proliferation, ALP and osteocalcin production. Our opinion is that gap junctional communication may serve as a means by which osteoblasts could function in synchrony and propagate locally generated signals throughout the skeletal tissue. Thus, we argue that $\mathrm{Mg}$ may enhance the GJIC between osteoblasts, and then promote the transfer of molecules between communicating cells. In this way, it would improve the response of osteoblasts to various stimulating signals. These data provide further support for the hypothesis that stimulatory effects of $\mathrm{Mg}$ ion on osteoblasts and osteogenesis activity are not only due to the direct binding and activation of their receptors, but also due to a direct action on the GJIC that coordinates bone remodeling.

Furthering our understanding of the mechanisms underlying the involvement of the $\mathrm{Mg}$ ion in the control of bone remodeling could lead to the development of therapies to improve bone mass in patients with diseases such as osteoporosis. However, the results reported here are preliminary. Many factors, such as the specificity and effective concentration of the $\mathrm{Mg}$ ion that are closer to the physiological state, should be taken into account in future work.

\section{Acknowledgments}

We are grateful to Liu Song for assistance with cell culture. We also would like to thank Dong Tianhua and Zhang Fei for their efforts in data preparation. This study received no financial support.

5. Weng L, Webster TJ. Nanostructured magnesium has fewer detrimental effects on osteoblast function. Int $\mathrm{J}$ Nanomedicine 2013; 8: 1773-1781, doi: 10.2147/IJN. S39031.

6. Lozano RM, Perez-Maceda BT, Carboneras M, OnofreBustamante E, Garcia-Alonso MC, Escudero ML. Response of MC3T3-E1 osteoblasts, L929 fibroblasts, and J774 macrophages to fluoride surface-modified AZ31 magnesium alloy. J Biomed Mater Res A 2013; 101: 2753-2762, doi: 10.1002/jbm.a.34579.

7. Rude RK, Wei L, Norton HJ, Lu SS, Dempster DW, Gruber HE. TNF-alpha receptor knockout in mice reduces adverse effects of magnesium deficiency on bone. Growth Factors 2009; 27: 370-376, doi: 10.3109/08977190903152644.

8. Rude RK, Singer FR, Gruber HE. Skeletal and hormonal effects of magnesium deficiency. J Am Coll Nutr 2009; 28: 131-141, doi: 10.1080/07315724.2009.10719764. 
9. Abed E, Moreau R. Importance of melastatin-like transient receptor potential 7 and magnesium in the stimulation of osteoblast proliferation and migration by platelet-derived growth factor. Am J Physiol Cell Physiol 2009; 297: C360-C368, doi: 10.1152/ajpcell.00614.2008.

10. Stains JP, Civitelli R. Cell-to-cell interactions in bone. Biochem Biophys Res Commun 2005; 328: 721-727, doi: 10.1016/j.bbrc.2004.11.078.

11. Wrobel E, Leszczynska J, Przybylski J. [Role of Gap junctions in bone tissue]. Postepy Biochem 2011; 57: 411-417.

12. Xu L, Pan F, Yu G, Yang L, Zhang E, Yang K. In vitro and in vivo evaluation of the surface bioactivity of a calcium phosphate coated magnesium alloy. Biomaterials 2009; 30: 1512-1523, doi: 10.1016/j.biomaterials.2008.12.001.

13. Ibasco S, Tamimi F, Meszaros R, Nihouannen DL, Vengallatore $\mathrm{S}$, Harvey $\mathrm{E}$, et al. Magnesium-sputtered titanium for the formation of bioactive coatings. Acta Biomater 2009; 5: 2338-2347, doi: 10.1016/j.actbio.2009.03.006.

14. Staiger MP, Pietak AM, Huadmai J, Dias G. Magnesium and its alloys as orthopedic biomaterials: a review. Biomaterials 2006; 27: 1728-1734, doi: 10.1016/j.biomaterials.2005.10.003.

15. Zreiqat $H$, Howlett $C R$, Zannettino A, Evans $P$, SchulzeTanzil G, Knabe $C$, et al. Mechanisms of magnesiumstimulated adhesion of osteoblastic cells to commonly used orthopaedic implants. J Biomed Mater Res 2002; 62: 175-184, doi: 10.1002/jbm.10270.

16. Vormann J. Magnesium: nutrition and metabolism. Mol Aspects Med 2003; 24: 27-37, doi: 10.1016/S0098-2997(02)00089-4.

17. Sul YT, Johansson C, Albrektsson T. Which surface properties enhance bone response to implants? Comparison of oxidized magnesium, TiUnite, and Osseotite implant surfaces. Int J Prosthodont 2006; 19: 319-328.

18. Sul YT, Johansson P, Chang BS, Byon ES, Jeong Y. Bone tissue responses to $\mathrm{Mg}$-incorporated oxidized implants and machine-turned implantsin the rabbit femur. J Appl Biomater Biomech 2005; 3: 18-28.

19. Sul $Y T$, Johansson $C B$, Kang $Y$, Jeon DG, Albrektsson $T$. Bone reactions to oxidized titanium implants with electrochemical anion sulphuric acid and phosphoric acid incorporation. Clin Implant Dent Relat Res 2002; 4: 78-87, doi: 10.1111/j.1708-8208.2002.tb00156.x.

20. Mackie EJ. Osteoblasts: novel roles in orchestration of skeletal architecture. Int J Biochem Cell Biol 2003; 35: 1301-1305, doi: 10.1016/S1357-2725(03)00107-9.
21. Yang C, Yuan G, Zhang J, Tang Z, Zhang X, Dai K. Effects of magnesium alloys extracts on adult human bone marrowderived stromal cell viability and osteogenic differentiation. Biomed Mater 2010; 5: 045005, doi: 10.1088/1748-6041/5/ 4/045005.

22. Leidi M, Dellera F, Mariotti M, Maier JA. High magnesium inhibits human osteoblast differentiation in vitro. Magnes Res 2011; 24: 1-6, doi: 10.1684/mrh.2011.0271.

23. Kircelli F, Peter ME, Sevinc OE, Celenk FG, Yilmaz M, Steppan S, et al. Magnesium reduces calcification in bovine vascular smooth muscle cells in a dose-dependent manner. Nephrol Dial Transplant 2012; 27: 514-521, doi: 10.1093/ ndt/gfr321.

24. Civitelli R. Cell-cell communication in the osteoblast/ osteocyte lineage. Arch Biochem Biophys 2008; 473: 188-192, doi: 10.1016/j.abb.2008.04.005.

25. Unger VM, Kumar NM, Gilula NB, Yeager M. Threedimensional structure of a recombinant gap junction membrane channel. Science 1999; 283: 1176-1180, doi: 10.1126/science.283.5405.1176.

26. Cherian PP, Siller-Jackson AJ, Gu S, Wang X, Bonewald LF, Sprague E, et al. Mechanical strain opens connexin 43 hemichannels in osteocytes: a novel mechanism for the release of prostaglandin. Mol Biol Cell 2005; 16: 3100-3106, doi: 10.1091/mbc.E04-10-0912.

27. McLachlan E, Plante I, Shao Q, Tong D, Kidder GM, Bernier $\mathrm{SM}$, et al. ODDD-linked Cx43 mutants reduce endogenous Cx43 expression and function in osteoblasts and inhibit late stage differentiation. J Bone Miner Res 2008; 23: 928-938, doi: 10.1359/jbmr.080217.

28. Watkins M, Grimston SK, Norris JY, Guillotin B, Shaw A, Beniash E, et al. Osteoblast connexin43 modulates skeletal architecture by regulating both arms of bone remodeling. Mol Biol Cell 2011; 22: 1240-1251, doi: 10.1091/mbc.E10-07-0571.

29. Lecanda F, Warlow PM, Sheikh S, Furlan F, Steinberg TH, Civitelli R. Connexin43 deficiency causes delayed ossification, craniofacial abnormalities, and osteoblast dysfunction. J Cell Biol 2000; 151: 931-944, doi: 10.1083/jcb.151. 4.931.

30. Chung DJ, Castro $\mathrm{CH}$, Watkins M, Stains JP, Chung MY, Szejnfeld VL, et al. Low peak bone mass and attenuated anabolic response to parathyroid hormone in mice with an osteoblast-specific deletion of connexin43. J Cell Sci 2006; 119: 4187-4198, doi: 10.1242/jcs.03162. 